\title{
The Future Has Already Happened
}

\author{
Alex Levant \\ Correspondence: alevant@wlu.ca
}

Alex Levant is Assistant Professor in the Department of Communication Studies at Wilfrid Laurier University in Waterloo, Canada. He specializes in critical media theory and emerging/future technologies. His work has appeared in various journals, including Historical Materialism, Critique, Stasis, Educational Review, among others. He is editor (with Vesa Oittinen) of Dialectics of the Ideal (Brill, 2014).

\begin{abstract}
This article interrogates current conceptions of thinking machines of the future. In contrast to dystopian visions of the future, where humans become dominated by machines of their own making, I argue that this future already happened some time ago, and that we are, in fact, already living in the future that we dread might come to pass.
\end{abstract}

Keywords: posthuman theory, artificial intelligence, capital, subjectivity

The impending emergence of thinking machines has become a commonplace in contemporary popular culture. If one were to judge on the basis of a spate of recent TV shows, such as Westworld (HBO), Humans (AMC), Black Mirror (Channel 4/Netflix), as well as films, such as Chappi, Blade Runner 2049, among others, it appears that it is just a matter of time before we find ourselves living amidst machines that, to varying degrees, will be able to think, feel, and even enter into relationships with us.

This article invites us to reflect on the nature of this imaginary by considering the thinking machine of the future not as a technological phenomenon, but as a socio-historical one. It suggests that the 'thinking machine' appears as a reasonable expectation of the future because of particular ways of understanding subjectivity that are current in popular culture, which typically reproduce the Cartesian mind/body dualism. Trends in contemporary posthuman theory challenge these dualist views; however, as I argue, they nevertheless tend to confirm this imaginary by reconceptualising matter itself as possessing a type of agency.

In contrast, the present analysis seeks to account for the agency of future machines in ways that posthuman theory does not. I want to suggest that we imagine smart machines of the future because today's machines already possess a 'phantom subjectivity'. This subjectivity, I contend, is unrelated to their technological capacities to replicate human subjectivity, but instead is a product of their commodification. Today's machines are animated not by technology, but by capital. In this piece, I interrogate current conceptions of thinking machines of the future, which I argue tend to obscure the present reality that today's machines already possess agency as commodities, and dominate us as we busy ourselves trying to ward off an impending doom that is always deferred. In a certain sense, the future is not here; rather, the future has already happened.

\section{i. Thinking Machines of the Future in Popular Culture}

In contemporary popular culture, the near-future tends to be imagined as including technologically advanced machines with human-like abilities and aspirations. However, such a future is far from certain, as it presupposes a particular understanding of subjectivity that posits the human mind as a 
spontaneous product of the brain, itself understood as a very fast computer. Consequently, one could imagine oneself as information that could be copied and transposed into another brain or into another computer that performs the functions of a brain. This view is an iteration of Descartes' mind/body dualism, where the mind appears as something immaterial that is housed in a material body. What was once seen as the soul is now seen as information—very different views with striking similarities, both rooted in a dualist approach.

In contrast, recent posthuman theory problematizes this dualism. For instance, Robert Pepperell (2009) in The Posthuman Condition: Consciousness Beyond the Brain argues that the brain necessarily exists in a body and that a body exists in an environment — all of which are necessary for the mind to exist. Such critiques are plentiful and persuasive, and in fact, one may wonder why we have so readily accepted the modelling of mind as information and brain as machine?

\section{ii. Posthuman Theory and the Agency of Machines}

While there is a substantial diversity of perspectives within posthuman theory, there appears to be a common rejection of Cartesian dualism. The mind/body dichotomy tends to be reconsidered, and the question of agency posed in new ways. Rethinking the relationship between human and nonhuman, and reimagining the nonhuman as possessing agency has been a recurring theme in recent theory. Machines have come to be understood as not only things humans use to achieve their objectives, but as having a part in shaping objectives. For instance, Actor-Network Theory (ANT) notes how technologies can prescribe certain behaviour. Bruno Latour refers to this as a 'prescription' written into technologies, which he defines as "the behavior imposed back onto the human by nonhuman" (Latour, "Missing Masses," 232). ANT attributes agency and even responsibility to these technologies. As Latour responds to the infamous NRA slogan 'Guns don't kill people. People kill people': 'It is neither people nor guns that kill. Responsibility for action must be shared among the various actants" (Latour, Pandora's Hope, 179-180).

This trend appears to be part of a larger theoretical shift, known as the 'material turn' (Levant). Following the 'linguistic turn' of the late $20^{\text {th }}$ century, which focused on the limits of human knowledge and challenged universal truth claims, in recent years, several theoretical approaches, which appeared separately, have sought to re-examine the enduring importance of matter (e.g. agential realism, new materialism, actor-network theory, postphenomenology, among others).

A particularly interesting example of a recent trend in posthuman theory is 'new materialism', which attributes not only agency to matter, as we saw with ANT, but also 'thought'. Rosi Braidotti describes 'new materialism' as follows: “A post-secular approach, posited on firm anti-humanist grounds... rests on the idea that matter, including the specific slice of matter that is human embodiment, is intelligent and self-organizing" (Braidotti 35). In posthuman theory, not only the machine, but matter itself appears already intelligent.

These theoretical trends are quite critical of the simplistic and dualist conceptions of subjectivity found in contemporary popular culture; however, they nevertheless confirm the imagined future where humans live alongside thinking machines. In posthuman theory, the issue tends to be rearticulated by ascribing agency to matter itself. Dualism is 'overcome' by subjectifying the object world (Levant). Machines appear to have agency not because of their ability to replicate 
the processing power of human neural networks, as in popular culture, but because matter naturally has agency. Similar to Braidotti, who attributes intelligence and self-organization to matter, for Latour matter also always already possesses agency; i.e. it does (Latour, "Missing Masses," 229).

Rather than critically analysing how dualist perspectives maintain a mystical understanding of mind (as a spontaneous product of the brain, for instance), trends in posthuman theory that ascribe mind to matter appear to further this mystification. In both cases, mind is simply just there, as a property of matter, or of a specific material object - quite consistent with the notion of intelligent machines. In contrast, I want to invite us to consider the smart machine of the future not as a matter of technological development, but a matter of political practice. What I am suggesting is that there is something about our 'ways of doing' that cultivates world views that make it quite reasonable to understand mind as a matter of computing.

\section{iii. Animated by Capital}

Evald Ilyenkov's work is useful for understanding how our practices shape our views. Ilyenkov eschews the mind/body split by advancing the concept of the thinking body:

There are not two different and originally contrary objects of investigation-body and thought - but only one single object, which is the thinking body [which] does not consist of two Cartesian halves — 'thought lacking a body' and a 'body lacking thought' [...] It is not a special 'soul,' installed by God in the human body as in a temporary residence, that thinks, but the body of man [sic] itself (Ilyenkov, Dialectical Logic, 18-19).

Drawing on Spinoza and Marx, Ilyenkov's thinking body refers not to the physical body of the individual, but to our collective or social body, of which the individual is a part. The thought of the social body is expressed in the ideal - a "special reality" (Ilyenkov, "Dial'ektika ideal'nogo," 14) comprised of immaterial phenomena, such as knowledge, mathematical truths, customs, tastes, etc. For Ilyenkov matter is idealized in the form of human activities that are codified in laws, cultural norms, and similar artifacts. These practices, inherited from the past, into which we are born, have a "peculiar objectivity", and confront us as objective social forces with which we must reckon no less than with the objective force of material objects.

Together, these practices constitute what Marx called a mode of production, which refers not only to an economic system, but to a way of doing, or a way of life. The organization of human activity under capitalism fosters an understanding of thought that reflects the logic of capital accumulation. When maximising profit becomes valued as the highest form of thought, then it becomes rational to value the instrumental reason of a thinking machine above all else, and to judge human abilities against this standard. In this regard, machines no longer appear as imperfect humans; rather, humans appear as imperfect machines.

This inversion between human and machine differs from the inversion imagined in popular culture, as machines are animated not by advanced technology, but by those very humans they dominate. Forgetting this reality is the essence of what Georg Lukacs called reification - the process by which social relations assume the appearance of things. He described it as follows: "Its basis is that a relation between people takes on the character of a thing and thus acquires a 'phantom

\footnotetext{
${ }^{1}$ See Ilyenkov, 2012.
} 
objectivity', an autonomy that seems so strictly rational and all-embracing as to conceal every trace of its fundamental nature: the relation between people" (Lukacs 83). When something is commodified, it acquires a new set of meanings that reflect the social relations in which this commodity moves. "It becomes a property of money to generate value and yield interest, much as it is an attribute of pear trees to bear pears" (Lukacs 94). As objects, in the form of commodities, acquire new powers, they also shed their previous meanings - anything that does not contribute to capital accumulation becomes extraneous and hence beyond the horizon of rational thought. The process of reification transforms social relations into things, and a living, mysterious world becomes encrusted in a second nature-a world in which things "acquire a new objectivity" (Lukacs 92)—where commodities attain magical powers, and where a magical, living world appears disenchanted and dead.

In this context, the commodified machine is something entirely different from a machine. Under capitalism, commodities become cells of capital, bearers of value (Marx). Their material properties become immaterial in this regard, although their value tends to appear as a product of these properties rather than as congealed human activity. As cells of capital, their 'objective' is to augment their value - which is the logic of their animation, or rather the objective of the investor seeking a return on their investment, which at the end of the day is capital, irrespective of what specific commodity it assumes at a given moment. But the source of their animation is human activity, itself commodified and directed by the force of the market. The commodified machine is first a commodity — a fact that transforms it from an ordinary object into one with a "phantom objectivity" that eclipses its material objectivity. But as the commodity form becomes ubiquitous, it becomes increasingly difficult to distinguish between things and commodities, and things increasingly appear as naturally possessing value. Similarly, with the agency of machines.

The agency of machines as commodities is not taken up by posthuman theory, which focuses on the material properties of objects rather than their peculiar objectivity as commodities. Failing to distinguish between objects and commodities, such approaches tend to mistake commodities for objects and hence contribute to ascribing agency to the object rather than the commodity. For instance, Latour writes, "every time you want to know what a nonhuman does, simply imagine what other humans or other nonhumans would have to do were this nonhuman not present" (Latour, "Missing Masses", 229). To this, we would want to add that if you want to know what the nonhuman does, examine what other humans or nonhumans would be able to do were this nonhuman not a commodity. This question points beyond the horizon afforded by our present way of doing, namely capitalism.

\section{iv. The Future Has Already Happened}

An analysis of the agency of machines as commodities raises the question that perhaps the attribution of agency to matter in posthuman theory is related to the actual empowerment of matter today in the form of capital? The ongoing commodification of matter involves practices that cultivate conceptions of thinking machines as both rational and natural. It appears that the expectation that we are on the precipice of the emergence of new forms of nonhuman intelligence may, in fact, occlude the reality that these nonhuman agents already exist as commodities — the cells of capital. 


\section{Works Cited}

Braidotti, Rosi. The Posthuman. Polity Press, 2013.

Ilyenkov, Evald. Dialectical Logic: Essays on Its History and Theory. Translated by H. Campbell

Creighton, Progress, 1977[1974].

. "Dialectics of the Ideal" [2009]. Trans. Alex Levant. Historical Materialism, vol. 20, no. 2, 2012, pp. 149-93.

. "Dial'ektika ideal'nogo" [Dialectics of the ideal]. Logos, vol. 69, no.1, 2009, pp. 6-62.

Latour, Bruno. Pandora's Hope: Essays on the Reality of Science Studies, Harvard University Press, 1999.

. "Where Are the Missing Masses? The Sociology of a Few Mundane Artifacts." Shaping Technology/Building Society: Studies in Sociotechnical Change. Edited by Wiebe E. Bijker and John Law, MIT Press, 1992, pp. 225-58.

Levant, Alex. "Smart Matter and the Thinking Body: Activity Theory and the Turn to Matter in Contemporary Philosophy," Stasis, vol. 4, no. 2, 2017, pp. 248-264.

Lukacs, Georg. History and Class Consciousness, The Merlin Press, 1971.

Marx, Karl. Capital: Critique of Political Economy, Marxist.org, 1887[1867]. www.marxists.org/archive/marx/works/1867-c1/index.htm.

Pepperell, Robert. The Posthuman Condition: Consciousness Beyond the Brain, Intellect Books, 2009. 